\title{
Surfactant for Respiratory Distress Syndrome: New Ideas on a Familiar Drug with Innovative Applications
}

\author{
H.J. Niemarkt ${ }^{a}$ M.C. Hütten ${ }^{b}$ Boris W. Kramer ${ }^{b}$ \\ a Department of Pediatrics, Máxima Medical Center, Veldhoven, and ${ }^{b}$ Department of Pediatrics, Maastricht \\ University Medical Center, Maastricht, The Netherlands
}

\section{Keywords}

Surfactant administration · Preterm infant · Respiratory distress syndrome

\begin{abstract}
In the last 4 decades, advances in neonatology have led to a significant increase in the survival of preterm infants. One of the biggest advances was the introduction of surfactant replacement therapy for the treatment of respiratory distress syndrome. This is the main cause of respiratory insufficiency in preterm infants and is one of the major causes of perinatal morbidity and mortality. Surfactant replacement therapy is already a well-investigated and established therapy in neonatology. However, surfactant replacement therapy has progressed and been refined over recent decades, especially with the increasing care for preterm infants born before 26 weeks' gestational age and the recent clinical focus on avoiding mechanical ventilation. Clinical evidence is evolving on new types of surfactant, surfactant dosages, co-medication given before, with, or after surfactant replacement, and new technical advances regarding the mode of administration.
\end{abstract}

(c) 2017 The Author(s)

Published by S. Karger AG, Basel

\section{Introduction}

For some decades, surfactant replacement therapy has been a well-investigated and established therapy in neonatology. The recent clinical focus on avoiding mechanical ventilation and the care of infants of less than 26 weeks' gestation has spurred new approaches of surfactant administration.

Surfactant is a complex mixture of lipids and proteins that reduces surface tension ("surface active agents"). Surfactant contains the saturated phospholipid dipalmitoylphosphatidylcholine (DPPC) and surfactant proteins (SP) A, B, C, and D, which account for approximately $10 \%$ of the weight. DPPC constitutes the largest fraction in weight (40-50\%), but surfactant also includes unsaturated phosphatidylcholines (20-25\%), phosphatidylglycerol (10\%), and other phospholipids [1-3].

The natural surfactants that are available for patient treatment are derived from bovine and porcine lungs. These surfactants differ in their composition and concentration of phospholipids and SP since they are lipid extractions that only contain SP-B and SP-C. From the beginning in surfactant research, attempts were made to develop a synthetic surfactant. Synthetic surfactant may have more consistent and predictable concentrations of

Prof. Boris W. Kramer

Department of Pediatrics

Maastricht University Medical Center

PO Box 5800, NL-6202 AZ Maastricht (The Netherlands)

E-Mail b.kramer@mumc.nl
This article is licensed under the Creative Commons AttributionNonCommercial-NoDerivatives 4.0 International License (CC BYNC-ND) (http://www.karger.com/Services/OpenAccessLicense). Usage and distribution for commercial purposes as well as any distribution of modified material requires written permission. 
the different components and may reduce the risk of animal-to-human infection, but have taken several steps in development to mimic the complexity of natural surfactants [4]. CHF 5633 is such a new third-generation synthetic surfactant containing $0.2 \%$ SP-B analog and $1.5 \%$ SP-C analog mixed with a DPPC:palmitoyloleoylphosph atidylglycerol ratio of $1: 1$ that has been tested in humans (NCT01651637; NCT02452476).

\section{Surfactant Dosing and Redosing}

Term infants have a surfactant storage pool of approximately $100 \mathrm{mg} / \mathrm{kg}$ of surfactant, while preterm infants have an estimated pool size of $4-5 \mathrm{mg} / \mathrm{kg}$ at birth [2]. In addition to the pool size, positive end expiratory pressure improves pulmonary distribution and augments the surface tension-lowering effects of surfactant [5-7].

Repetitive doses of exogenous surfactant administered as a bolus have been studied. A Cochrane Review demonstrated that a strategy of allowing multiple doses of natural surfactant rather than a single dose further reduces the risk of pneumothorax (RR 0.51, 95\% CI 0.3-0.88) and there is a trend towards a reduction in mortality. However, the studies included in this meta-analysis were performed in the early 1990s with lower use of antenatal corticosteroids and longer ventilation periods. Recent guidelines advise only the administration of a second dose if there is ongoing evidence of respiratory distress syndrome (RDS), such as the need for continued mechanical ventilation or oxygen dependence $[8,9]$.

However, the size of the first dose of surfactant is of clinical importance. Doses between $50 \mathrm{mg} / \mathrm{kg}$ of beractant (phospholipid concentration $50 \mathrm{mg} / \mathrm{mL}$ ) and 200 $\mathrm{mg} / \mathrm{kg}$ of poractant alfa $(80 \mathrm{mg} / \mathrm{mL})$ have been studied. Infants who received $50 \mathrm{mg} / \mathrm{kg}$ of beractant compared to $100 \mathrm{mg} / \mathrm{kg}$ were more often non-responders and in need of a second dose of surfactant [10]. Other clinical studies compared $100 \mathrm{mg} / \mathrm{kg}$ doses of 1 product with 100 and $200 \mathrm{mg} / \mathrm{kg}$ doses of another product [11]. The concentration of surfactant, however, determines the amount of surfactant that can be deposited as a bolus since the volume of the trachea of a small preterm infant is restricted. Therefore, doses beyond $100 \mathrm{mg} / \mathrm{kg}$ could only be studied with the more concentrated poractant alfa. Post hoc analysis of studies that compared beractant and poractant alfa demonstrated that poractant alfa administered at high doses of $200 \mathrm{mg} / \mathrm{kg}$ compared to a lower dose of $100 \mathrm{mg} / \mathrm{kg}$ led to increased survival and decreased intraventricular hemorrhage (IVH). Besides, redosing was

Surfactant for Respiratory Distress Syndrome needed less frequently [11-14], probably due to the longer half-life of DPPC when administered at the higher $200 \mathrm{mg} / \mathrm{kg}$ dose.

The surfactant dosage in less invasive surfactant administration techniques (which are discussed later) has not yet been studied. However, it must be taken into account that when surfactant is administered with a feeding tube a significant amount (11\%) of material is lost in the tube [15]. The dose dependency of the clinical response with a minimally invasive surfactant technique was confirmed in a recent study by Dargaville et al. [16], where all infants who received poractant alfa at a dose of $200 \mathrm{mg} /$ $\mathrm{kg}$ did not have to be ventilated in the first $72 \mathrm{~h}$ of life.

\section{When Should Surfactant Be Given?}

The first clinical trials with surfactant were performed in preterm infants who were ventilated because of RDS. Less than half of these infants received antenatal corticosteroids. These studies demonstrated that early surfactant administration (at $\left.\mathrm{FiO}_{2}<0.45\right)$ was superior to late $\left(\mathrm{FiO}_{2}\right.$ $>0.45$ ) administration [17-19]. This led to a strategy of early intubation of very preterm infants in the delivery room and prophylactic surfactant administration from the 1990s onwards.

However, empirical evidence that continuous positive airway pressure (CPAP) treatment was associated with low rates of bronchopulmonary dysplasia (BPD) led to renewed interest in CPAP. The use of CPAP, antenatal corticosteroids (which attenuate RDS and the need for exogenous surfactant), and the treatment of younger infants with very vulnerable lungs have created a dilemma in the delivery room [20]: is it better to intubate these infants and give prophylactic surfactant or manage them on CPAP?

Several large clinical trials (COIN, SUPPORT, and VON-DRM) have addressed this question [21-23]. It was concluded that it was better to start with CPAP support in the delivery room if possible and intubate and administer surfactant only to infants with signs of RDS [21-23]. Other studies compared CPAP to prophylactic surfactant treatment with the Intubate-Surfactant-Extubate (INSURE) approach. During INSURE, infants are intubated, receive surfactant, and are supposed to be immediately extubated to minimize mechanical ventilation, if necessary antagonising any sedation that was used for intubation. These studies also did not find a benefit of prophylactic surfactant with INSURE over CPAP [21, 24, $25]$. A possible explanation may be that even short peri-

Neonatology 2017;111:408-414 DOI: $10.1159 / 000458466$ 


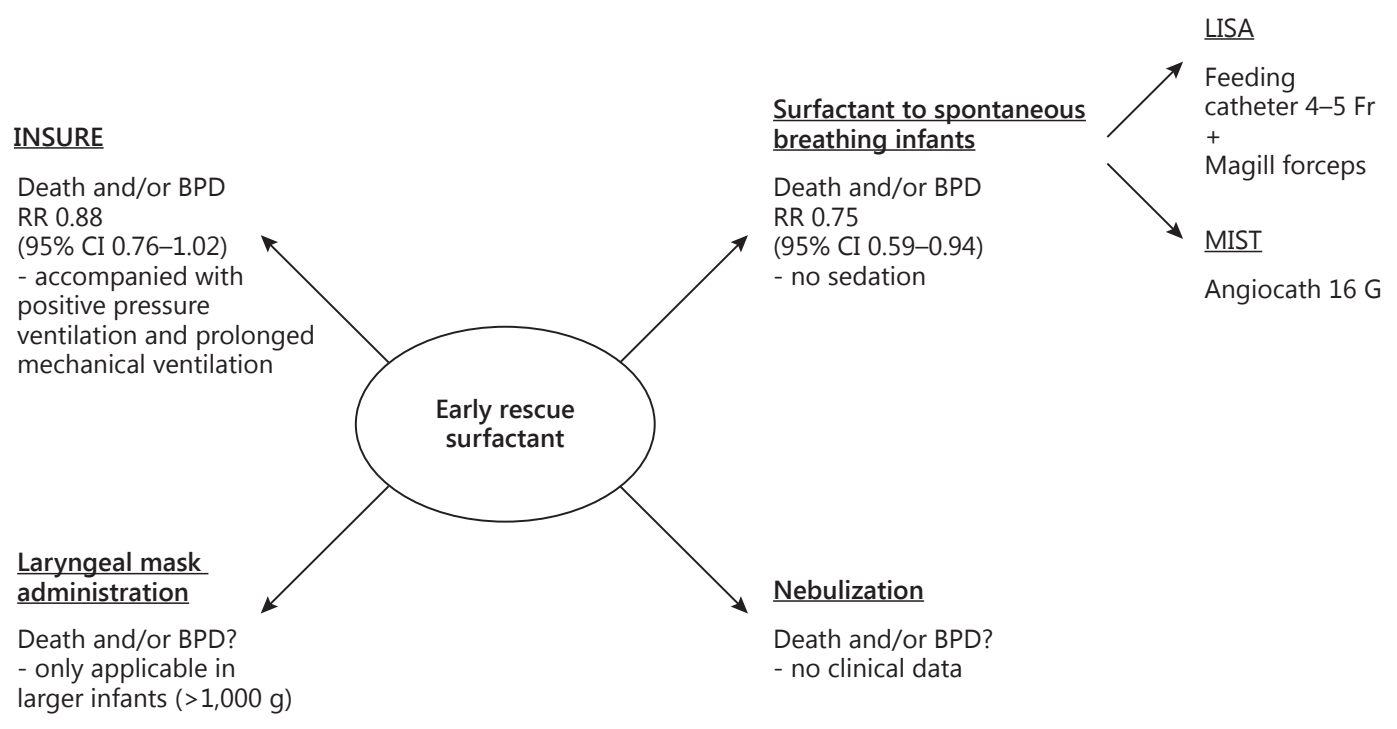

Fig. 1. Different modalities of surfactant administration. Recent guidelines advise the administration of surfactant as early rescue therapy. Surfactant administration to infants with spontaneous breathing leads to a reduction in BPD and/or death (RR 0.75, 95\% CI 0.59-0.94) compared to standard treatment. Currently there are
2 different practices: LISA (surfactant administration through a feeding tube placed between the vocal cords with Magill forceps) and MIST (surfactant administration through a stiff vascular catheter placed between the vocal cords). ods of mechanical ventilation can damage the vulnerable lung. Many of the infants in whom INSURE was performed were ventilated for a longer period [26]. Moreover, INSURE turned out to be difficult to implement in other neonatal units. Many, mainly extremely preterm infants, who were treated with INSURE failed to be extubated after surfactant administration, leading to a longer time on ventilation. Brix et al. [26] demonstrated that more than $60 \%$ of preterm infants treated with INSURE failed to be extubated $2 \mathrm{~h}$ after the procedure. Meta-analyses have demonstrated that prophylactic INSURE did not lead to a higher survival without BPD $[27,28]$. A new modified INSURE with an alveolar recruitment manoeuvre before surfactant administration is currently being investigated [29].

Meta-analyses that have incorporated this new evidence demonstrate that selective use of surfactant versus prophylactic use of surfactant leads to a decrease in BPD and/or death [27]. Recent evidence still demonstrates that early rescue surfactant $(<2 \mathrm{~h}$ after birth) versus late rescue surfactant $(>2 \mathrm{~h}$ after birth) is associated with a reduction in BPD and/or death [30]. Therefore, the American Academy of Pediatrics and the European guidelines on surfac- tant administration advise stabilization of preterm infants on CPAP and, if necessary, the administration of surfactant as early rescue therapy, preferably within 2 $3 \mathrm{~h}$ after birth $[8,9]$.

The clinical dilemma which arises from this practice is that a subgroup of infants fail CPAP therapy and have to be intubated at a later time. These infants miss the advantages of early surfactant and suffer a higher incidence of BPD and IVH [31]. Various studies have investigated whether CPAP failure can be predicted [31-34]. Predictors of CPAP failure included male sex and low birth weight, but most importantly $\mathrm{FiO}_{2}$ above $0.30-0.35$ in the first $2 \mathrm{~h}$ of life. The availability of new techniques of surfactant administration may make it easier to provide earlier treatment.

\section{New Techniques of Surfactant Administration}

New techniques of surfactant administration in combination with CPAP may offer a way to avoid mechanical ventilation completely [8, 9, 35] (Fig. 1). A less invasive technique of administering surfactant with a small cath- 
eter instead of an endotracheal tube to infants breathing spontaneously may combine the benefits of CPAP (which avoids mechanical ventilation) and early surfactant treatment [36]. The first feasibility study was performed by Kribs et al. [37] in Cologne. In this procedure, named less invasive surfactant administration (LISA), a thin catheter is placed in the trachea with the aid of Magill forceps under direct laryngoscopy. This procedure is embedded in a whole package of interventions aimed at the avoidance of positive pressure ventilation, especially during transition and the first $72 \mathrm{~h}$ of life [36]. This package includes antenatal steroids, early CPAP, and caffeine treatment in the delivery room [38]. During this technique CPAP is continued as the distribution of surfactant is dependent on alveolar recruitment [7]. LISA leads to an immediate increase in end-expiratory lung volume and oxygenation in preterm infants on CPAP [39]. LISA may lead to better surfactant distribution and better lung compliance as infants keep spontaneously breathing [40]. Surfactant distribution in LISA-treated lambs was compared to lambs who were intubated and received surfactant [41]. Although in the LISA-treated lambs surfactant deposition in the lungs was lower and surfactant distribution differed slightly, with less surfactant being delivered to the right upper lung, oxygenation improved in a similar way compared to the lambs who were intubated and received surfactant.

The first randomised trial (AMV study) of the German Neonatal Network (GNN), which included preterm infants born at gestational age 26-29 weeks, demonstrated a risk reduction in the need for mechanical ventilation during the first $72 \mathrm{~h}$ [42]. Besides, infants treated with LISA had fewer days on mechanical ventilation and less oxygen need at the 28th day of life compared to infants who were treated conventionally. As the infants were recruited immediately after birth, not all needed surfactant [42].

In a later randomised trial (NINSAPP study), infants with a gestational age of 24-28 weeks in need of surfactant were included. This study did not show a reduction in $\mathrm{BPD}$ and/or death as the primary endpoint. However, the LISA-treated infants showed a higher rate of survival without major complications (BPD, NEC, pneumothorax, and severe IVH grade 3/4) compared to the control group. In particular, the relative reduction of $50 \%$ in severe IVH was striking. Although not a primary endpoint, this study confirmed a large reduction in the need for mechanical ventilation during the first days of life [43].

Large observational studies supported these findings but they also demonstrated a reduction in BPD [44, 45].
However, there is still variability in the application of this technique regarding indications, catheter type, redosing, and the use of premedication $[46,47]$.

In 2011 the procedure was modified by Dargaville et al. [48], who used a rigid adult vascular catheter (16-G Angiocath; BD Medical, Sandy, UT, USA) to avoid use of the Magill forceps. This method was named minimally invasive surfactant therapy (MIST) and was evaluated in 2 observational trials showing similar results to the first LISA studies [48, 49]. A large international multicentre trial (OPTIMIST) using this method is currently recruiting (NCT02140580).

Although LISA and MIST vary in certain aspects, recent meta-analyses combining the different trials with these methods demonstrated a reduction in BPD and/or death in infants (RR $0.75,95 \%$ CI $0.59-0.94$ ) who were treated with LISA/MIST [50-52]. The absence of premedication during placement of the catheter in infants receiving LISA/MIST is still a point of intense debate. A recent retrospective study compared the administration of propofol $(1 \mathrm{mg} / \mathrm{kg})$ to no sedation in 38 preterm infants, of whom 23 received MIST [53]. The administration of propofol was left at the discretion of the attending neonatologist. Infants who received propofol showed lower pain scores, but more needed positive pressure ventilation and/or intubation. Therefore, administration of premedication may diminish the positive effects of LISA/ MIST.

The laryngeal mask (LMA) is a supraglottic device that is usually used to apply positive pressure ventilation for a short time. In 2004, surfactant administration using a LMA was first described in a case report by Brimacombe et al. [54]. A pilot randomized controlled trial in 26 preterm infants with birth weight $>1,200 \mathrm{~g}$ compared surfactant given by LMA to CPAP and found a marked decrease in oxygen requirement in infants who received surfactant via LMA [55]. Other trials compared surfactant via LMA to the INSURE method. Sadeghnia et al. [56] performed a study in infants with a birth weight over 2,000 g and observed better oxygenation in infants who received surfactant via LMA, but no difference in the need for mechanical ventilation.

Pinheiro et al. [57] investigated surfactant via LMA versus INSURE in infants with birth weights $>1,000 \mathrm{~g}$. Treatment failure was decreased in the LMA group (30\%) compared to the INSURE group (77\%). This might be due to the fact that failure was defined as the need for mechanical ventilation or antagonising drugs. Infants with surfactant per LMA did not receive premedication, allowing them to keep breathing spontaneously. Although the 
trial demonstrated that placement of the LMA was perceived as easy by experienced users, more than 1 attempt was often needed to place it correctly. In addition, surfactant reflux and coughing were frequently observed [36]. LMA placement has not yet been proven feasible in the smallest of infants who most profit from less invasive surfactant administration methods.

To optimize the technique of administering surfactant less invasively, some clinical scientists have combined different methods or tools. Recently, a study (CALMEST) was published which combined use of an LMA as a guide for a LISA catheter to administer surfactant [58]. Also, Poets and colleagues [59] developed a special soft catheter to administer surfactant less invasively without Magill forceps.

These approaches reduce the size of the device that is put through the vocal cords but do not eliminate it. Surfactant administration by nebulization is therefore in theory the most elegant, as it is truly non-invasive. However, this technique has many practical issues: the particle size has to be very small $(0.5-2.0 \mu \mathrm{m})$, the substance must remain intact during nebulization, and the loss/misplacement of the expensive surfactant in the upper airways and/or oesophagus must be kept to a minimum in order to reduce costs. Besides, as the nebulized surfactant only distributes to the ventilated parts of the lung, nebulization may lead to an inhomogeneous surfactant distribution.

Different nebulizers have been tested in animal models and in clinical settings for this purpose. Older studies with jet nebulizers with very low pulmonary deposition $(<1 \%)$ of surfactant do not show convincing clinical results $[36,60,61]$. Recently, the emergence of vibrating perforated membrane nebulizers have provided significant improvements for aerosolization. Aerosol droplets are generated by a perforated vibrating mesh which can be adjusted to the physicochemical properties of the drug. Consequently, these devices markedly increase the proportion of aerosolized drug delivered to the patient [62]. Surfactant nebulization with perforated membrane nebulizers was tested in a feasibility trial [63] and in an animal model. Longer nebulization of higher doses of surfactant in humidified air improved oxygenation and lung mechanics. Surfactant was delivered to all lung lobes, with a preference to the lower lobes when given at high doses [64]. However, the yield of the nebulized surfactant into the lungs was very poor. Pillow and Minocchieri [62] performed a clinical trial in infants $>29$ weeks' gestational age (ANZCTR 12610000857000) but the results have not been published yet. Currently, a phase II single-centre study is recruiting infants with RDS to investigate nebulized surfactant (NCT 02294630).

\section{Surfactant in Combination with Medication Administration}

\section{Budesonide}

As inflammation plays a major part in the development of BPD, corticosteroid therapy has been investigated extensively for its treatment and prevention. Due to side effects and the lack of clinical evidence on the drug, dose, duration, and start of therapy, more organ-directed corticosteroid therapy with inhaled budesonide has been investigated, with conflicting results on mortality [65]. However, surfactant may be a good vehicle for corticosteroid delivery to the lung. Yeh et al. [66] performed a pilot study in which 116 very low birth weight infants with severe RDS needing mechanical ventilation were treated with surfactant combined with budesonide. This treatment resulted in lower combined BPD and death rates (31.7\%) compared to surfactant only $(60.7 \%, p=0.003)$. In a $2-3$ year follow-up no neurocognitive adverse effects were detected after combined surfactant and budesonide treatment. A recent trial of 265 low birth weight infants, also by Yeh and colleagues [67], confirmed these promising results. In the intervention group (surfactant with budesonide) the combined BPD and death rate was $42 \%$ compared to $66 \%$ in controls (surfactant alone). The number needed to treat was 4.1 $(2.8-7.8, p<0.001)$ and no adverse effects were noticed [68]. This approach has not been studied with less invasive surfactant administration techniques.

\section{Future Directions}

The following aspects may form the focus of future research. Early identification of infants who need surfactant is of importance, and the disadvantages of late surfactant administration should be prevented. Furthermore, as new methods of minimally invasive surfactant administration are emerging, prophylactic surfactant with LISA may have advantages over CPAP with rescue administration of surfactant by LISA in very preterm infants $<26$ weeks' gestational age, who are very often in need of surfactant. However, this has to be investigated in large clinical trials.

The best minimally invasive method of surfactant administration has to be identified. Currently there is a large variability between indications and methods for less invasive surfactant treatment. We need to identify the groups of patients who benefit most or who do not benefit from this technique, the right dose of surfactant, type of surfactant, indication for repeating surfactant administration (intubation or reperforming less invasive technique), use 
of catheters (with the development and testing of new special catheters for less invasive surfactant administration), and the use of premedication, in order to get the most out of this innovation for the appropriate patient population.

\section{Disclosure Statement}

The authors have nothing to disclose.

\section{References}

1 Parra E, Perez-Gil J: Composition, structure and mechanical properties define performance of pulmonary surfactant membranes and films. Chem Phys Lipids 2015;185:153-175.

-2 Sardesai S, Biniwale M, Wertheimer F, Garingo A, Ramanathan R: Evolution of surfactant therapy for respiratory distress syndrome: past, present, and future. Pediatr Res 2017;81:240-248.

3 Jobe A: Pharmacology review: why surfactant works for respiratory distress syndrome. Neoreviews 2006; 95 .

4 Curstedt T, Calkovska A, Johansson J: New generation synthetic surfactants. Neonatology 2013;103:327-330.

5 Davis AJ, Jobe AH, Hafner D, Ikegami M: Lung function in premature lambs and rabbits treated with a recombinant SP-C surfactant. Am J Resp Crit Care Med 1998;157:553-559.

6 Michna J, Jobe AH, Ikegami M: Positive endexpiratory pressure preserves surfactant function in preterm lambs. Am J Resp Crit Care Med 1999;160:634-639.

$\checkmark 7$ Krause MF, Jakel C, Haberstroh J, SchulteMonting J, Leititis JU, Orlowska-Volk M: Alveolar recruitment promotes homogeneous surfactant distribution in a piglet model of lung injury. Pediatr Res 2001;50:34-43.

-8 Polin RA, Carlo WA: Surfactant replacement therapy for preterm and term neonates with respiratory distress. Pediatrics 2014;133:156163.

-9 Sweet DG, Carnielli V, Greisen G, Hallman M, Ozek E, Plavka R, Saugstad OD, Simeoni U, Speer CP, Vento M, Visser GH, Halliday HL: European consensus guidelines on the management of respiratory distress syndrome - 2016 update. Neonatology 2017;111: 107-125.

10 Gortner L, Pohlandt F, Bartmann P, Bernsau U, Porz F, Hellwege HH, Seitz RC, Hieronimi G, Kuhls E, Jorch G, et al: High-dose versus low-dose bovine surfactant treatment in very premature infants. Acta Paediatr 1994;83: 135-141.

11 Ramanathan R, Rasmussen MR, Gerstmann DR, Finer N, Sekar K; North American Study Group: A randomized, multicenter masked comparison trial of poractant alfa (Curosurf) versus beractant (Survanta) in the treatment of respiratory distress syndrome in preterm infants. Am J Perinatol 2004;21:109-119.

12 Singh N, Hawley KL, Viswanathan K: Efficacy of porcine versus bovine surfactants for preterm newborns with respiratory distress syndrome: systematic review and meta-analysis. Pediatrics 2011;128:e1588-e1595.
13 Singh N, Halliday HL, Stevens TP, Suresh G, Soll R, Rojas-Reyes MX: Comparison of animal-derived surfactants for the prevention and treatment of respiratory distress syndrome in preterm infants. Cochrane Database Syst Rev 2015;12:CD010249.

14 Halliday HL, Tarnow-Mordi WO, Corcoran JD, Patterson CC: Multicentre randomised trial comparing high and low dose surfactant regimens for the treatment of respiratory distress syndrome (the Curosurf 4 trial). Arch Dis Child 1993;69:276-280.

15 De Luca D, Minucci A, Gentile L, Capoluongo ED: Surfactant inadvertent loss using feeding catheters or endotracheal tubes. Am J Perinatol 2014;31:209-212.

16 Dargaville PA, Aiyappan A, De Paoli AG, Dalton RG, Kuschel CA, Kamlin CO, Orsini F, Carlin JB, Davis PG: Continuous positive airway pressure failure in preterm infants: incidence, predictors and consequences. Neonatology 2013;104:8-14.

17 Bevilacqua G, Halliday H, Parmigiani S, Robertson B: Randomized multicentre trial of treatment with porcine natural surfactant for moderately severe neonatal respiratory distress syndrome. The Collaborative European Multicentre Study Group. J Perinat Med 1993;21:329-340.

18 Stevens TP, Harrington EW, Blennow M, Soll RF: Early surfactant administration with brief ventilation vs. selective surfactant and continued mechanical ventilation for preterm infants with or at risk for respiratory distress syndrome. Cochrane Database Syst Rev 2007;4:CD003063.

19 Verder H, Albertsen P, Ebbesen F, Greisen G, Robertson B, Bertelsen A, Agertoft L, Djernes B, Nathan E, Reinholdt J: Nasal continuous positive airway pressure and early surfactant therapy for respiratory distress syndrome in newborns of less than 30 weeks' gestation. Pediatrics 1999;103:E24.

20 Pfister RH, Soll RF: Initial respiratory support of preterm infants: the role of CPAP, the INSURE method, and noninvasive ventilation. Clin Perinatol 2012;39:459-481.

21 Dunn MS, Kaempf J, de Klerk A, de Klerk R, Reilly M, Howard D, Ferrelli K, O'Conor J, Soll RF; Vermont Oxford Network DRM Study Group: Randomized trial comparing 3 approaches to the initial respiratory management of preterm neonates. Pediatrics 2011; 128:e1069-e1076.

22 Morley CJ, Davis PG, Doyle LW, Brion LP, Hascoet JM, Carlin JB, Investigators CT: Nasal CPAP or intubation at birth for very preterm infants. N Engl J Med 2008;358:700-708.
23 SUPPORT Study Group of the Eunice Shriver NICHD Neonatal Research Network: Early CPAP versus surfactant in extremely preterm infants. N Engl J Med 2010;362:1970-1979.

24 Rojas MA, Lozano JM, Rojas MX, Laughon M, Bose CL, Rondon MA, Charry L, et al; Colombian Neonatal Research Network: Very early surfactant without mandatory ventilation in premature infants treated with early continuous positive airway pressure: a randomized, controlled trial. Pediatrics 2009; 123:137-142.

25 Sandri F, Plavka R, Ancora G, Simeoni U, Stranak Z, Martinelli S, Mosca F, Nona J, Thomson M, Verder H, Fabbri L, Halliday H: Prophylactic or early selective surfactant combined with nCPAP in very preterm infants. Pediatrics 2010;125:e1402-e1409.

26 Brix N, Sellmer A, Jensen MS, Pedersen LV, Henriksen TB: Predictors for an unsuccessful INtubation-SURfactant-Extubation procedure: a cohort study. BMC Pediatr 2014;14: 155.

27 Rojas-Reyes MX, Morley CJ, Soll R: Prophylactic versus selective use of surfactant in preventing morbidity and mortality in preterm infants. Cochrane Database Syst Rev 2012;3: CD000510.

28 Isayama T, Chai-Adisaksopha C, McDonald SD: Noninvasive ventilation with vs without early surfactant to prevent chronic lung disease in preterm infants: a systematic review and meta-analysis. JAMA Pediatr 2015;169: 731-739.

29 Vento G, Pastorino R, Boni L, Cota F, Carnielli V, Cools F, Dani C, et al: Efficacy of a new technique - INtubate-RECruit-SURfactantExtubate - "IN-REC-SUR-E" - in preterm neonates with respiratory distress syndrome: study protocol for a randomized controlled trial. Trials 2016;17:414.

30 Bahadue FL, Soll R: Early versus delayed selective surfactant treatment for neonatal respiratory distress syndrome. Cochrane Database Syst Rev 2012;11:CD001456.

- 31 Dargaville PA, Gerber A, Johansson S, De Paoli AG, Kamlin CO, Orsini F, Davis PG; Australian, New Zealand Neonatal Network: Incidence and outcome of CPAP failure in preterm infants. Pediatrics 2016;138: e20153985.

- 32 Ammari A, Suri M, Milisavljevic V, Sahni R, Bateman D, Sanocka U, Ruzal-Shapiro C, Wung JT, Polin RA: Variables associated with the early failure of nasal CPAP in very low birth weight infants. J Pediatr 2005;147:341347.
Surfactant for Respiratory Distress

Syndrome
Neonatology 2017;111:408-414 DOI: $10.1159 / 000458466$ 
$\checkmark 33$ De Jaegere AP, van der Lee JH, Cante C, van Kaam AH: Early prediction of nasal continuous positive airway pressure failure in preterm infants less than 30 weeks gestation. Acta Paediatr 2012;101:374-379.

-34 Fuchs H, Lindner W, Leiprecht A, Mendler MR, Hummler HD: Predictors of early nasal CPAP failure and effects of various intubation criteria on the rate of mechanical ventilation in preterm infants of $<29$ weeks gestational age. Arch Dis Child Fetal Neonatal Ed 2011; 96:F343-F347.

35 Verder H, Agertoft L, Albertsen P, Christensen NC, Curstedt T, Ebbesen F, Greisen G, Hobolth N, Holm V, Jacobsen T, et al: Surfactant treatment of newborn infants with respiratory distress syndrome primarily treated with nasal continuous positive air pressure: a pilot study (in Danish). Ugeskr Laeger 1992; 154:2136-2139.

36 Kribs A: Minimally invasive surfactant therapy and noninvasive respiratory support. Clin Perinatol 2016;43:755-771.

-37 Kribs A, Pillekamp F, Hunseler C, Vierzig A, Roth B: Early administration of surfactant in spontaneous breathing with nCPAP: feasibility and outcome in extremely premature infants (postmenstrual age $\leq 27$ weeks). Paediatr Anaest 2007;17:364-369.

$>38$ Mehler K, Grimme J, Abele J, Huenseler C, Roth B, Kribs A: Outcome of extremely low gestational age newborns after introduction of a revised protocol to assist preterm infants in their transition to extrauterine life. Acta Paediatr 2012;101:1232-1239.

-39 van der Burg PS, de Jongh FH, Miedema M, Frerichs I, van Kaam AH: Effect of minimally invasive surfactant therapy on lung volume and ventilation in preterm infants. J Pediatr 2016;170:67-72.

40 Bohlin K, Bouhafs RK, Jarstrand C, Curstedt T, Blennow M, Robertson B: Spontaneous breathing or mechanical ventilation alters lung compliance and tissue association of exogenous surfactant in preterm newborn rabbits. Pediatr Res 2005;57:624-630.

-41 Niemarkt HJ, Kuypers E, Jellema R, Ophelders D, Hutten M, Nikiforou M, Kribs A, Kramer BW: Effects of less-invasive surfactant administration on oxygenation, pulmonary surfactant distribution, and lung com pliance in spontaneously breathing preterm lambs. Pediatr Res 2014;76:166-170.

-42 Gopel W, Kribs A, Ziegler A, Laux R, Hoehn T, Wieg C, Siegel J, et al; German Neonatal Network: Avoidance of mechanical ventilation by surfactant treatment of spontaneously breathing preterm infants (AMV): an openlabel, randomised, controlled trial. Lancet 2011;378:1627-1634

-43 Kribs A, Roll C, Gopel W, Wieg C, Groneck P, Laux R, Teig N, et al; NINSAPP Trial Investigators: Nonintubated surfactant application vs conventional therapy in extremely preterm infants: a randomized clinical trial. JAMA Pe diatr 2015;169:723-730.
44 Gopel W, Kribs A, Hartel C, Avenarius S, Teig N, Groneck P, Olbertz D, et al; German Neonatal Network: Less invasive surfactant administration is associated with improved pulmonary outcomes in spontaneously breathing preterm infants. Acta Paediatr 2015;104: 241-246.

45 Klebermass-Schrehof K, Wald M, Schwindt J, Grill A, Prusa AR, Haiden N, Hayde M, Waldhoer T, Fuiko R, Berger A: Less invasive surfactant administration in extremely preterm infants: impact on mortality and morbidity. Neonatology 2013;103:252-258.

46 Heiring C, Jonsson B, Andersson S, Bjorklund LJ: Survey shows large differences between the Nordic countries in the use of less invasive surfactant administration. Acta Paediatr 2017;106:382-386.

47 Klotz D, Porcaro U, Fleck T, Fuchs H: European perspective on less invasive surfactant administration - a survey. Eur J Pediatr 2017; 176:147-154.

-48 Dargaville PA, Aiyappan A, Cornelius A, Williams C, De Paoli AG: Preliminary evaluation of a new technique of minimally invasive surfactant therapy. Arch Dis Child Fetal Neonatal Ed 2011;96:F243-F248.

49 Dargaville PA, Aiyappan A, De Paoli AG, Kuschel CA, Kamlin CO, Carlin JB, Davis PG: Minimally-invasive surfactant therapy in preterm infants on continuous positive airway pressure. Arch Dis Child Fetal Neonatal Ed 2013;98:F122-F126.

50 Aldana-Aguirre JC, Pinto M, Featherstone RM, Kumar M: Less invasive surfactant administration versus intubation for surfactant delivery in preterm infants with respiratory distress syndrome: a systematic review and meta-analysis. Arch Dis Child Fetal Neonatal Ed 2017;102:F17-F23.

51 Rigo V, Lefebvre C, Broux I: Surfactant instillation in spontaneously breathing preterm infants: a systematic review and meta-analysis. Eur J Pediatr 2016;175:1933-1942.

-52 Isayama T, Iwami H, McDonald S, Beyene J: Association of noninvasive ventilation strategies with mortality and bronchopulmonary dysplasia among preterm infants: a systematic review and meta-analysis. JAMA 2016; 316:611-624.

53 Dekker J, Lopriore E, Rijken M, Rijntjes-Jacobs E, Smits-Wintjens V, Te Pas A: Sedation during minimally invasive surfactant therapy in preterm infants. Neonatology 2016;109: 308-313.

54 Brimacombe J, Gandini D, Keller C: The laryngeal mask airway for administration of surfactant in two neonates with respiratory distress syndrome. Paediatr Anaes 2004;14: 188-190.

55 Attridge JT, Stewart C, Stukenborg GJ, Kattwinkel J: Administration of rescue surfactant by laryngeal mask airway: lessons from a pilot trial. Am J Perinatol 2013;30:201-206.

-56 Sadeghnia A, Tanhaei M, Mohammadizadeh M, Nemati M: A comparison of surfactant ad- ministration through i-gel and ET-tube in the treatment of respiratory distress syndrome in newborns weighing more than 2,000 g. Adv Biomed Res 2014;3:160.

57 Pinheiro JM, Santana-Rivas Q, Pezzano C: Randomized trial of laryngeal mask airway versus endotracheal intubation for surfactant delivery. J Perinatol 2016;36:196-201.

58 Vannozzi I, Ciantelli M, Moscuzza F, Scaramuzzo RT, Panizza D, Sigali E, Boldrini A, Cuttano A: Catheter and laryngeal mask endotracheal surfactant therapy: the CALMEST approach as a novel MIST technique. J Matern Fetal Neonatal Med 2016, Epub ahead of print.

59 Maiwald CA, Neuberger P, Vochem M, Poets C: QuickSF: a new technique in surfactant administration. Neonatology 2016;111:211213.

60 Berggren E, Liljedahl M, Winbladh B, Andreasson B, Curstedt T, Robertson B, Schollin J: Pilot study of nebulized surfactant therapy for neonatal respiratory distress syndrome. Acta Paediatr 2000;89:460-464.

61 Jorch G, Hartl H, Roth B, Kribs A, Gortner L, Schaible T, Hennecke KH, Poets C: Surfactant aerosol treatment of respiratory distress syndrome in spontaneously breathing premature infants. Pediatr Pulmonol 1997;24:222-224.

62 Pillow JJ, Minocchieri S: Innovation in surfactant therapy II: surfactant administration by aerosolization. Neonatology 2012;101:337344.

63 Finer NN, Merritt TA, Bernstein G, Job L, Mazela J, Segal R: An open label, pilot study of Aerosurf ${ }^{\circledR}$ combined with nCPAP to prevent RDS in preterm neonates. J Aerosol Med Pulm Drug Deliv 2010;23:303-309.

64 Hutten MC, Kuypers E, Ophelders DR, Nikiforou M, Jellema RK, Niemarkt HJ, Fuchs C, Tservistas M, Razetti R, Bianco F, Kramer BW: Nebulization of poractant alfa via a vibrating membrane nebulizer in spontaneously breathing preterm lambs with binasal continuous positive pressure ventilation. Pediatr Res 2015;78:664-669.

65 Bassler D: Inhaled budesonide for the prevention of bronchopulmonary dysplasia. J Matern Fetal Neonatal Med 2016, Epub ahead of print.

66 Yeh TF, Lin HC, Chang CH, Wu TS, Su BH, Li TC, Pyati S, Tsai CH: Early intratracheal instillation of budesonide using surfactant as a vehicle to prevent chronic lung disease in preterm infants: a pilot study. Pediatrics 2008; 121:e1310-e1318.

67 Kuo HT, Lin HC, Tsai CH, Chouc IC, Yeh TF: A follow-up study of preterm infants given budesonide using surfactant as a vehicle to prevent chronic lung disease in preterm infants. J Pediatr 2010;156:537-541.

68 Yeh TF, Chen CM, Wu SY, Husan Z, Li TC, Hsieh WS, Tsai CH, Lin HC: Intratracheal administration of budesonide/surfactant to prevent bronchopulmonary dysplasia. Am J Resp Crit Care Med 2016;193:86-95. 